\title{
Caracterización citológica de la médula ósea durante el desarrollo fetal en la alpaca (Vicugna pacos)
}

\author{
Cytological characterization of the bone marrow during fetal development \\ in the alpaca (Vicugna pacos)
}

Elvis Calderón F. ${ }^{1}$, Juan Espinoza B. ${ }^{2}$, Olga Li E. ${ }^{3}$, Manuel Barrios-Arpi ${ }^{4.5}$

\section{Resumen}

\begin{abstract}
El presente estudio tuvo como objetivo investigar la morfología y morfometría de las células progenitoras de la médula ósea a través del examen citológico durante el desarrollo fetal de la alpaca (Vicugna pacos). Se colectaron muestras de médula ósea provenientes de 18 fetos de alpacas clínicamente sanas y destinadas a beneficio en Pasco, Perú. Se seccionaron la octava y novena costillas tomando como referencia la unión costo-condral y se hicieron frotis con las muestras de médula ósea, que fueron coloreadas con la tinción Wright. Los porcentajes de celularidad para cada tercio de gestación fueron $16 \pm 0.2(\mathrm{n}=3), 35 \pm 0.16(\mathrm{n}=5)$ y $78 \pm 0.12(\mathrm{n}=10)$, respectivamente, evidenciándose las primeras células hematopoyéticas a partir de los 201.5 días de edad. Mediante el conteo diferencial de 500 células se estableció la relación mieloide:eritroide, siendo de $0,0.47 \pm 0.27$ y $0.69 \pm 0.19$ para el primer, segundo y tercer tercio de gestación, respectivamente. En el segundo tercio de gestación se detectó $10.17 \%$ de células eritroides, $5.03 \%$ de células mieloides y $84.80 \%$ de otros tipos celulares, mientras que en el último tercio fue de $39.99 \%$ de células eritroides, $26.99 \%$ de células mieloides y $33.21 \%$ de otros tipos celulares. En el examen morfométrico, las células hematopoyéticas revelaron características similares a las encontradas en otras especies.
\end{abstract}

Palabras clave: alpaca, feto, médula ósea, citología

${ }^{1}$ Clínica de Animales Menores, Facultad de Medicina Veterinaria, Universidad Nacional Mayor de San Marcos, Lima, Perú

${ }^{2}$ Laboratorio de Farmacología y Toxicología Veterinaria, Facultad de Medicina Veterinaria, Universidad Nacional Mayor de San Marcos, Lima, Perú

${ }^{3}$ Laboratorio de Patología Clínica y Biología Molecular, Facultad de Medicina Veterinaria, Universidad Nacional Mayor de San Marcos, Lima, Perú

${ }^{4}$ Laboratorio de Fisiología Animal, Facultad de Medicina Veterinaria, Universidad Nacional Mayor de San Marcos, Lima, Perú

${ }^{5}$ E-mail: lbarriosa@unmsm.edu.pe

Recibido: 14 de abril de 2019

Aceptado para publicación: 2 de junio de 2020

Publicado: 11 de agosto de 2020 
The present study aimed to investigate the morphology and morphometry of progenitor cells from the bone marrow through cytological examination during foetal development of the alpaca (Vicugna pacos). Bone marrow samples were collected from 18 culled and clinically healthy alpaca foetuses in Pasco, Peru. The eighth and ninth ribs were removed using the cost-chondral junction as reference and smears were made with the bone marrow samples, and then stained with Wright. The percentages of cellularity for each third of pregnancy were $16 \pm 0.2(n=3), 35 \pm 0.16(n=5)$ and $78 \pm 0.12(n=10)$, respectively, showing the first hematopoietic cells from 201.5 days old. Through the differential count of 500 cells, the myeloid: erythroid ratio was established, being $0.47 \pm$ 0.27 and $0.69 \pm 0.19$ for the first, second and last third of pregnancy, respectively. In the second third of pregnancy $10.17 \%$ of erythroid cells, $5.03 \%$ of myeloid cells and $84.80 \%$ of other cell types were detected, while in the last third it was $39.99 \%$ of erythroid cells, $26.99 \%$ of myeloid cells and $33.21 \%$ of other cell types. In the morphometric examination, hematopoietic cells revealed characteristics like those found in other species.

Key words: alpaca, fetus, bone marrow, cytology

\section{INTRODUCCIÓN}

Los camélidos sudamericanos incluyen a la llama (Lama glama) y la alpaca (Vicugna pacos) como especies domésticas y al guanaco (Lama guanicoe) y la vicuña (Vicugna vicugna) como especies silvestres. Estos animales forman parte de la actividad pecuaria en las zonas altoandinas de Perú, Argentina, Chile y Bolivia (Mendoza et al., 2013). Si bien los mecanismos de adaptación hematológicos a la altura han sido estudiados, especialmente en alpacas (Quispe, 2011), existe escasa información sobre el rol de la médula ósea en la hematopoyesis de estas especies, habiendo sido estudiada principalmente con fines diagnósticos y descriptivos en animales adultos o enfermos (Andreasen et al., 1994; Tornquist, 2009).

La médula ósea se localiza en las cavidades de los cuerpos vertebrales, costillas, esternón, huesos del cráneo, pelvis y epífisis proximales del fémur y húmero (siendo los huesos largos los de mayor actividad hematopoyética) (Grindem et al., 2002). En este órgano se producen los eritrocitos, granulocitos, monocitos y plaquetas. Si bien en los vertebrados, luego del nacimiento, la médula ósea se comporta como un nicho hematopoyético, durante la embriogénesis las células precursoras de la hematopoyesis $(\mathrm{CPH})$, emergen y migran a través de diferentes tejidos (Coskun y Hirschi, 2010). En el ratón, las primeras células sanguíneas observadas son unos eritroblastos grandes y nucleados en el saco vitelino extraembrionario en el día 8 del desarrollo gestacional (Palis et al., 1999), en tanto que la placenta y la región aorta-gónadas-mesonefros (AGM) exhiben células con potencial hematopoyético en el día 10 (Gekas et al., 2005). Así mismo, las CPH se encuentran en el hígado fetal en el día 11 (Morrison y Weissman, 1994), y finalmente las células ya desarrolladas, con morfología y funcionabilidad similares en adultos se encuentran en la médula ósea al día 16 del desarrollo fetal (Coskun et al., 2014).

Andreasen et al. (1994) caracterizó citológicamente la médula ósea de siete llamas adultas aparentemente normales, encontrando entre 50 y $75 \%$ de células hematopoyéticas mediante aspirado de médula ósea, donde la morfología y maduración de las cé- 
lulas eritroides fueron similares a la observada en camellos (Naziji y Maleki, 1998). Estas células fueron inicialmente redondas, para luego cambiar a una forma más elíptica, mientras se hacían menos policro-matófilas, en tanto que las células mieloides y megacariocitos tuvieron secuencias de morfología y maduración típicas. La relación mieloideeritroide $(\mathrm{M} / \mathrm{E})$ promedio en la médula ósea de los camélidos adultos sanos es similar a la de otras especies (Harvey, 2010), habiéndose reportado de 0.9 a 2.9 en llamas y de 0.47 a 1.01 en alpacas (Tornquist, 2009).

El objetivo del presente estudio fue caracterizar citológicamente la médula ósea a través de la evaluación cualitativa (observacional) y cuantitativa (observacional y morfométrica) de las células precursoras hematopoyéticas durante el desarrollo fetal en la alpaca (Vicugna pacos).

\section{MATERIALES Y MÉTOdoS}

Se emplearon 18 fetos, siendo 3, 5 y 10 tres fetos del primer, segundo y tercer tercio de la gestación, respectivamente. Los fetos fueron obtenidos de alpacas gestantes de descarte destinadas al beneficio en el matadero Municipal de Ninacaca, departamento de Cerro de Pasco, Perú, a 4140 msnm, entre febrero y marzo de 2017. La edad gestacional de los fetos se determinó mediante el diámetro biparietal (DBP), medido con un vernier Litz ${ }^{\circledR}$, aplicando la fórmula de Gazitua et al. (2001): Edad gestacional = (DBP0.11376 )*47.23287, $\mathrm{r}=0.98, \mathrm{p}<0.001$, donde DBP: Diámetro biparietal fetal en centímetros, $r$ : coeficiente de regresión, p: nivel de significancia.

Con el fin de garantizar que las muestras de médula ósea de los fetos procedan de hembras gestantes clínicamente sanas, se colectaron muestras de sangre periférica (3 $\mathrm{ml}$ ) en el momento del sacrificio (vena yugular) en un tubo de muestra con EDTA, para realizar el hemograma correspondiente.
Los fetos fueron retirados de las bolsas amnióticas. Se palpó la zona costal, teniendo como puntos de referencia la $7^{\circ}, 8^{\circ}$ y $9^{\circ}$ unión costocondral. El área justo por encima de la unión costocondral fue elegida para la extracción de 2 a $3 \mathrm{~cm}$ de las costillas $8^{\circ}$ o $9^{\circ}$. Con una pinza hemostática se presionaron uno de los extremos del fragmento costal a fin de depositar una gota de médula ósea en una lámina portaobjetos y se procedió a realizar la extensión por la técnica de aplastamiento. Se prepararon tres láminas con muestras de médula ósea de cada feto de alpaca. Las láminas fueron teñidas con colorante Wright para la evaluación citológica.

Para la evaluación de la celularidad (composición celular de una muestra citológica), se determinó la cantidad de células por campo expresado en porcentaje. Para la determinación de la relación mieloide: eritroide (cociente entre el número total de células precursoras nucleadas mieloides y eritroides) se realizaron tres conteos diferenciales de 500 células por cada muestra de médula ósea de feto para clasificar y caracterizar las células precursoras hematopoyéticas. Las células precursoras eritroides incluyeron rubriblastos, prorrubricitos, rubricitos y metarrubricitos, y las mieloides incluyeron mieloblastos, promielocitos, mielocitos, metamielocitos, abastonados y segmentados. Otras células caracterizadas fueron las células precursoras trombocíticas (megacarioblastos, promegacariocitos y megacariocitos), osteoblastos, osteoclastos, células linfoides, macrófagos y mastocitos.

Se determinó el índice de maduración eritroide a partir de la sumatoria de células eritroides en fase de maduración dividido por la suma total de células eritroides en fase de proliferación. Así mismo, se determinó el índice de maduración mieloide a partir de la sumatoria de células mieloides en fase de maduración dividido por la suma total de células mieloides en fase proliferativa. Finalmente, se realizaron cinco mediciones de los diámetros longitudinal y transversal por cada una 
de las células precursoras. Las mediciones fueron procesadas con el software de medición y microfotografía LAS X 3.0 (Leica, Alemania).

\section{Resultados y Discusión}

Durante el desarrollo embrionario y fetal en mamíferos, las células precursoras hematopoyéticas emergen y luego migran a través de diferentes tejidos y órganos. Arias et al. (2011) describieron mediante evaluación histológica, agrupaciones de células correspondientes a nidos hematopoyéticos esplénicos en un feto de alpaca de 55 días de gestación. Además, se ha reportado la presencia de células hematopoyéticas en el timo de fetos de alpaca a partir de los 100 días de gestación (Montenegro, 2006). La médula ósea interviene activamente en la hematopoyesis a mediados de la gestación en la mayoría de los mamíferos (Coskun et al., 2014). En el presente estudio, se evidenciaron células hematopoyéticas en médula ósea en los fetos de segundo (Cuadro 1) y último tercio de gestación (Cuadro 2) de características morfológicas y morfométricas (Figura 1, Cuadro 3) similares a las descritas en adultos a partir de un feto de 201.5 días de edad gestacional (perteneciente al segundo tercio de gestación).

Si bien no existe estudios sobre la ontogenia de la médula ósea en la alpaca, Tiedemann y van Ooyen (1978) reportaron que la médula ósea era funcional en fetos de gatos al día 35 de gestación; así mismo, PessaMorikawa et al. (2012) concluyeron que la médula ósea de fetos de bovinos presentaba un alto potencial progenitor de células hematopoyéticas entre los 180 y 255 días de gestación; mientras que Battista et al. (2014) demostraron en el día 100 de gestación de fetos de equino que el hígado y la médula ósea eran sitios activos de hematopoyesis, basados en marcadores moleculares de diferenciación para leucocitos y mensajeros de señal para diferenciación de células hemato- poyéticas. Estas últimas son especies de gestación larga (bovinos: 9 meses; equinos: 11 meses) al igual que la alpaca en el presente estudio, lo cual explica la escasa celularidad observada en el primer tercio de gestación $(16 \pm 0.2 \%)$ (Cuadro 4$)$, habiendo únicamente células indiferenciadas y algunos macrófagos (Cuadro 5), mientras que la celularidad aumentó a $35 \pm 0.16 \%$ en el segundo tercio de gestación y a $78 \pm 0.12 \%$ en el último tercio de gestación. Este último valor concuerda con reportes de animales jóvenes (Andreasen et al., 1994).

Se pudo identificar células pertenecientes a la serie eritroide, siendo el rubriblasto (prorubricitos, rubricitos y metarubricitos) la primera célula identificable citológicamente (Figura 2). También se pudo identificar células mieloides como: mieloblastos, promielocitos y mielocitos, a partir de las cuales se clasificaron en basófilos, neutrófilos y eosinófilos de acuerdo con las características de sus gránulos citoplasmáticos (Figuras 3, 4 y 5). Por otro lado, en la serie trombocítica, los megacariocitos se identificaron como las células más grandes en el presente estudio y presentaron múltiples lobulaciones nucleares (Figura 6). Además, se pudo identificar células óseas como osteoblastos (Figura 7) y osteoclastos (Figura 8).

El porcentaje de macrófagos en el segundo y último tercio de gestación $(2.54 \pm$ 0.98 y $1.44 \pm 0.7 \%$, respectivamente) pueden estar relacionados con el alto número de metarubricitos, ya que en cada isla eritroide conformada en su mayoría por metarubricitos y demás precursores eritroides, está presente un macrófago encargado de la fagocitosis de los núcleos extruidos para dar origen al eritrocito maduro. Además, las células linfoides se encontraron en bajo número en el recuento diferencial: $0.55 \pm 1.52$ y $1.36 \pm$ $0.63 \%$ para el segundo y último tercio de gestación, respectivamente, con respecto a lo reportado por Andreasen et al. (1994), lo cual permite deducir que la médula ósea no interviene de forma primaria durante el desarrollo 
Cuadro 1. Composición porcentual citológica de médula ósea de cinco fetos de alpaca (Vicugna pacos) en el segundo tercio de gestación

\begin{tabular}{|c|c|c|}
\hline Tipo de célula & Promedio (\%) & Desviación estándar \\
\hline Rubroblasto & 0.17 & 0.20 \\
\hline Prorubricito & 0.32 & 0.58 \\
\hline Rubricito basofilo & 1.19 & 2.89 \\
\hline Rubricito policromatófilo & 2.78 & 2.55 \\
\hline Metarubricito & 5.71 & 6.18 \\
\hline Total de células eritrocíticas & 10.17 & \\
\hline Mieloblasto & 0.10 & 0.06 \\
\hline Promielocito & 0.14 & 0.06 \\
\hline Mielocito neutrófilo & 0.34 & 1.21 \\
\hline Metamielocito neutrófilo & 0.67 & 1.27 \\
\hline Abastonado neutrófilo & 0.23 & \\
\hline Segmentado neutrófilo & 1.84 & 2.24 \\
\hline Mielocito eosinófilo & 0.22 & 0.08 \\
\hline Metamielocito eosinófilo & 0.30 & 0.04 \\
\hline Abastonado eosinófilo & 0.40 & 0.20 \\
\hline Segmentado eosinófilo & 0.76 & 1.87 \\
\hline Mielocito basófilo & 0.00 & 0.00 \\
\hline Metamielocito basófilo & 0.04 & 0.06 \\
\hline Abastonado basófilo & 0 & 0 \\
\hline Segmentado basófilo & 0 & 0 \\
\hline Total de células granulocíticas & 5.03 & \\
\hline Osteoblastos & 55.50 & 8.00 \\
\hline Osteoclastos & 2.30 & 0.74 \\
\hline Megacarioblasto & 0.04 & 0.00 \\
\hline Promegacariocito & 0 & 0.02 \\
\hline Megacariocito & 0.08 & 0.02 \\
\hline Células linfoides & 0.55 & 1.52 \\
\hline Mastocitos & 0 & \\
\hline Macrófagos & 2.54 & 0.98 \\
\hline Células indiferenciadas & 23.80 & 15.58 \\
\hline Total de otras células & 84.80 & \\
\hline
\end{tabular}


Cuadro 2. Composición porcentual citológica de médula ósea de 10 fetos de alpaca (Vicugna pacos) en el último tercio de gestación

\begin{tabular}{|c|c|c|}
\hline Tipo de célula & Promedio $(\%)$ & Desviación estándar \\
\hline Rubroblasto & 0.98 & 0.43 \\
\hline Prorubricito & 1.54 & 0.79 \\
\hline Rubricito basofilo & 4.94 & 1.02 \\
\hline Rubricito policromatófilo & 8.71 & 3.34 \\
\hline Metarubricito & 23.82 & 6.98 \\
\hline Total de células eritrocíticas & 39.99 & \\
\hline Mieloblasto & 0.59 & 0.42 \\
\hline Promielocito & 0.82 & 0.55 \\
\hline Mielocito neutrófilo & 1.16 & 0.52 \\
\hline Metamielocito neutrófilo & 1.55 & 0.72 \\
\hline Abastonado neutrófilo & 7.95 & 4.25 \\
\hline Segmentado neutrófilo & 9.00 & 3.86 \\
\hline Mielocito eosinófilo & 0.72 & 0.43 \\
\hline Metamielocito eosinófilo & 0.69 & 0.43 \\
\hline Abastonado eosinófilo & 1.66 & 0.66 \\
\hline Segmentado eosinófilo & 2.16 & 0.75 \\
\hline Mielocito basófilo & 0.16 & 0.12 \\
\hline Metamielocito basófilo & 0.12 & 0.10 \\
\hline Abastonado basófilo & 0.15 & 0.12 \\
\hline Segmentado basófilo & 0.25 & 0.18 \\
\hline Total de células granulocíticas & 26.99 & \\
\hline Osteoblastos & 22.18 & 8.19 \\
\hline Osteoclastos & 1.35 & 0.56 \\
\hline Megacarioblasto & 0.18 & 0.06 \\
\hline Promegacariocito & 0.21 & 0.10 \\
\hline Megacariocito & 0.41 & 0.07 \\
\hline Células linfoides & 1.36 & 0.63 \\
\hline Mastocitos & 0.12 & 0.10 \\
\hline Macrófagos & 1.44 & 0.70 \\
\hline Células indiferenciadas & 5.96 & 3.95 \\
\hline Total de otras células & 33.21 & \\
\hline
\end{tabular}




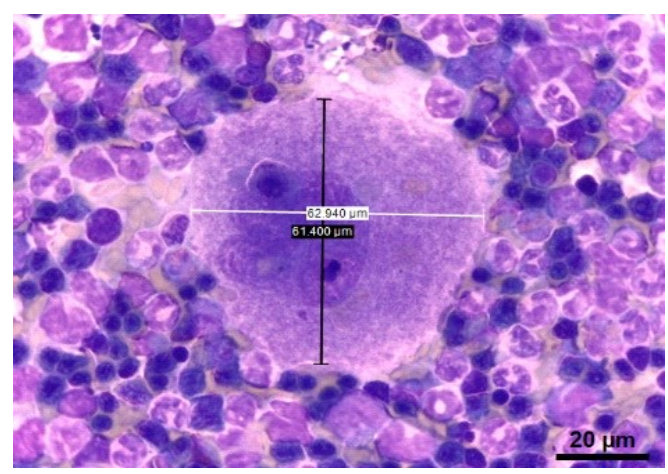

Figura 1. Morfometría de un megacariocito en médula ósea fetal de alpaca (Vicugna pacos) de 309 días (diámetro longitudinal: $61.4 \mu \mathrm{m}$, diámetro trasversal: $62.94 \mu \mathrm{m}$ ). Tinción Wright. 100x

fetal como tejido linfoide, sino que existen otros órganos como el timo e hígado que cumplen este rol desde los primeros estadios embrionarios (Montenegro, 2006; Arias et al., 2011).

El elevado porcentaje de células indiferenciadas de las muestras de médula ósea con respecto a los reportes de otros autores (Andreasen et al., 1994; Tornquist, 2009; Harvey, 2010), puede deberse a que se hicieron en animales adultos, los cuales presentan un desarrollo total de los componentes externos de la médula ósea. En el presente estudio, las estructuras que conforman la médula ósea fetal se encuentran aún en formación y, por eso, es fácil encontrar restos de células reticulares, vasculares y condrocíticas que pierden su forma característica al momento de realizar el frotis, impidiendo su reconocimiento.

Los índices de maduración mieloide (Cuadro 6) (metamielocitos, abastonados y segmentados) para el segundo y tercer tercio gestacional fueron de 9.4 y 6.8 , respectivamente, muy diferente al valor expuesto por Martínez de Merlo (2008) de $4.4 \pm 1.4$. Esto está relacionado con el $26.99 \%$ de células granulocíticas que componen el recuento di- ferencial para el último tercio de gestación, valores bajos para el $63.22 \%$ para llamas adultas reportado por Andreasen et al. (1994) y de $37.9 \%$ en 24 caballos sanos indicado por Jain (1986). El bajo porcentaje de células granulocíticas en el último tercio de gestación del presente estudio está relacionado al alto porcentaje de células de la línea eritroide; posiblemente debido a la adaptación evolutiva de esta especie a las condiciones adversas de su entorno, que conlleva a priorizar el transporte de oxígeno mediante un aumento del recuento total de eritrocitos circulantes (Fowler, 2011).

El índice de maduración eritroide (metarubricitos) de 3.28 y 3.47 para el segundo y tercer tercio gestacional, respectivamente (Cuadro 6) se aproxima al valor de $5.2 \pm 1.7$ expuesto por Martínez de Merlo (2008). El porcentaje de metarubricitos en el último tercio de gestación $(23.82 \pm 6.98 \%)$ fue más alto que lo reportado en otros mamíferos (Jain, 1986). Esta característica podría estar relacionada a la rápida respuesta eritropoyética que presentan los camélidos sudamericanos frente a procesos anémicos y a la evidencia ocasional de metarubricitos en extendidos de sangre periférica en llamas (Smith et al., 1991; Morin et al., 1993).

La relación mieloide-eritroide en equinos varió entre 0.5 y 2.4. En bovinos, la relación $\mathrm{M} / \mathrm{E}$ es baja (0.5-0.6), en cabras se reportaron valores similares y en ovejas es de 1 . Los valores bajos en estos rumiantes se correlacionan con el bajo número de neutrófilos en sangre periférica comparado con otras especies y la velocidad a la que se agotan los neutrófilos durante procesos inflamatorios (Harvey, 2010; Weiss y Wardrop, 2011). En el presente estudio el elevado porcentaje de precursores eritroides en médula ósea y el bajo porcentaje de células granulocíticas dieron como resultado que la relación $\mathrm{M} / \mathrm{E}$ promedio en el segundo y tercer tercio de gestación fuera de $0.47 \pm 0.27$ y $0.69 \pm 0.19$, respectivamente (Cuadro 7), los cuales difieren estadísticamente bajo la prueba de Mann-Whitney, (Cuadro 8). Estos 
Cuadro 3. Promedio $(\mu \mathrm{m})$ de diámetros longitudinal (L) y trasversal (T) de los tipos de células observadas en muestras citológicas de médula ósea de 18 fetos de alpaca (Vicugna pacos) de diferentes edades gestacionales

\begin{tabular}{lcccc}
\hline Célula & Diámetro L & $\mathrm{DE}^{1} \mathrm{~L}$ & Diámetro T & $\mathrm{DE}^{1} \mathrm{~T}$ \\
\hline Rubroblasto & 18.25 & 1.94 & 16.64 & 1.12 \\
Prorubricito & 12.69 & 1.29 & 10.60 & 1.42 \\
Rubricito basofilo & 10.28 & 0.62 & 8.30 & 0.51 \\
Rubricito policromatófilo & 8.16 & 0.52 & 6.75 & 0.54 \\
Metarubricito & 5.13 & 0.53 & 4.46 & 0.56 \\
Mieloblasto & 16.38 & 0.96 & 12.20 & 0.44 \\
Promielocito & 16.37 & 1.01 & 15.39 & 1.80 \\
Mielocito neutrófilo & 12.47 & 1.06 & 11.28 & 0.85 \\
Metamielocito neutrófilo & 10.82 & 1.89 & 9.48 & 1.30 \\
Abastonado neutrófilo & 9.40 & 1.71 & 7.66 & 1.77 \\
Segmentado neutrófilo & 9.42 & 1.35 & 8.06 & 1.94 \\
Mielocito eosinófilo & 13.32 & 1.73 & 10.48 & 0.91 \\
Metamielocito eosinófilo & 11.23 & 2.03 & 9.74 & 1.58 \\
Abastonado eosinófilo & 10.79 & 2.34 & 9.27 & 1.55 \\
Segmentado eosinófilo & 9.50 & 1.08 & 8.04 & 1.73 \\
Mielocito basófilo & 13.78 & 2.18 & 11.06 & 2.25 \\
Metamielocito basófilo & 10.28 & 1.42 & 10.02 & 1.71 \\
Abastonado basófilo & 10.36 & 1.47 & 9.06 & 1.23 \\
Segmentado basófilo & 10.68 & 0.86 & 7.48 & 0.80 \\
Megacarioblasto & 48.32 & 6.39 & 38.66 & 3.09 \\
Promegacariocito & 64.95 & 4.51 & 53.55 & 6.74 \\
Megacariocito & 77.02 & 6.68 & 67.52 & 7.17 \\
Osteoblastos & 21.70 & 4.39 & 14.90 & 1.51 \\
Osteoclastos & 52.73 & 13.91 & 59.65 & 15.78 \\
Células linfoides & 9.88 & 1.69 & 7.82 & 2.51 \\
Mastocitos & 9.08 & 1.38 & 7.77 & 1.69 \\
Macrófagos & 15.63 & 2.31 & 14.29 & 1.51 \\
Células indiferenciadas & 9.83 & 3.75 & 8.36 & 2.60 \\
\hline & & & & \\
\hline
\end{tabular}

DE: Desviación estándar 
Cuadro 4. Porcentaje de celularidad de muestras de médula ósea de 18 fetos de alpaca (Vicugna pacos) según el tercio de gestación

\begin{tabular}{lccc}
\hline $\begin{array}{c}\text { Tercio } \\
\text { de } \\
\text { gestación }\end{array}$ & Feto & $\begin{array}{c}\text { Edad } \\
\text { (días) }\end{array}$ & $\begin{array}{c}\text { Celularidad } \\
(\%)\end{array}$ \\
\hline Primer & 1 & 75.2 & 18 \\
& 2 & 86.7 & 15 \\
& 3 & 96.2 & 15 \\
Segundo & 4 & 121.5 & 20 \\
& 5 & 138.7 & 25 \\
& 6 & 141.0 & 25 \\
& 7 & 201.5 & 50 \\
& 8 & 219.2 & 55 \\
Tercer & 9 & 251.3 & 55 \\
& 10 & 253.9 & 70 \\
& 11 & 267.6 & 70 \\
& 12 & 278.7 & 75 \\
& 13 & 288.4 & 75 \\
& 14 & 289.6 & 85 \\
& 15 & 308.7 & 80 \\
& 16 & 311.3 & 90 \\
& 17 & 334.0 & 85 \\
& 18 & 337.1 & 95 \\
\hline
\end{tabular}

Cuadro 5. Composición porcentual citológica de médula ósea de tres fetos ${ }^{1}$ de alpaca (Vicugna pacos) en el primer tercio de gestación

\begin{tabular}{|c|c|c|}
\hline & $\begin{array}{c}\text { Promedio } \\
(\%)\end{array}$ & $\begin{array}{c}\text { Desviación } \\
\text { estándar }\end{array}$ \\
\hline Macrófagos & 3.04 & 1.27 \\
\hline $\begin{array}{c}\text { Células } \\
\text { indiferenciadas }\end{array}$ & 96.96 & 2.78 \\
\hline
\end{tabular}

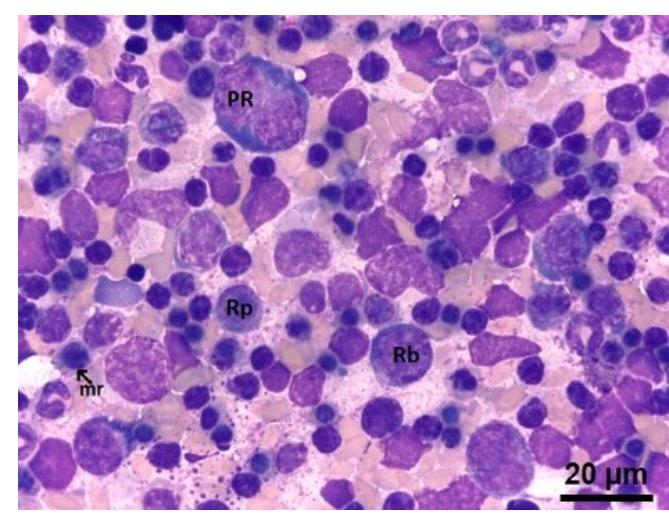

Figura 2. Células precursoras de la serie eritroide en médula ósea de feto de alpaca de 267.6 días: (PR) Prorubricito en mitosis. Nótese el citoplasma intensamente basófilo. $(\mathrm{Rb})$ Rubricito basófilo. Nótese la disminución de la basofília. (Rp) Rubricito policromatófilo. (Mr) Metarubricito. Nótese en las tres últimas células el núcleo con tendencia a volverse cada vez más picnótico. Tinción Wright.100x

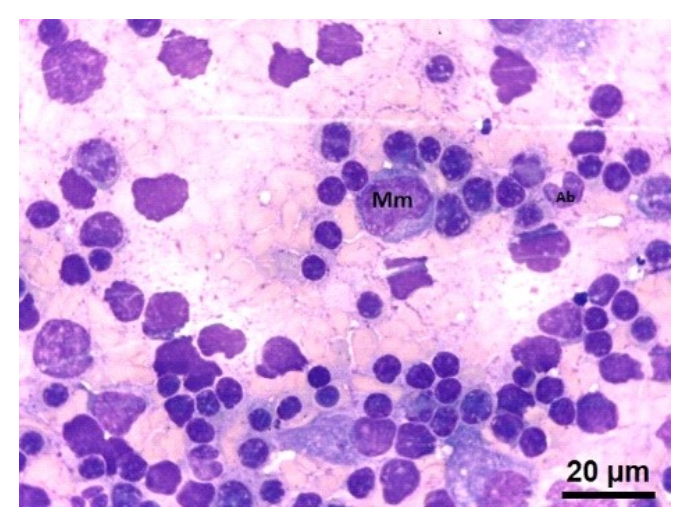

Figura 3. Células precursoras de la serie mieloide en médula ósea de feto de alpaca de 267.6 días: (Mm) Metamielocito neutrófilo. Nótese la ligera escotadura en el núcleo. (Ab) Abastonado neutrófilo. Tinción Wright.100x

valores se encuentran dentro del rango de 0.5 a 1.11 reportado para alpacas a 4200 msnm (Reynafarje et al., 1968), mientras que en altitudes más bajas ha sido reportada con rangos de 0.9 a 2.9 en llamas sanas (Andrea- 
Cuadro 6. Índice de maduración eritroide y mieloide (cociente de precursores en maduración entre los precursores en fase proliferativa) en fetos de alpaca (Vicugna pacos) en el segundo y último tercio de gestación

\begin{tabular}{lcc}
\hline & $\begin{array}{c}\text { Segundo tercio } \\
(\%)\end{array}$ & $\begin{array}{c}\text { Tercer tercio } \\
(\%)\end{array}$ \\
\hline Rubroblastos & 1.72 & 2.46 \\
Prorubricitos & 3.18 & 3.84 \\
Rubricitos basófilos & 11.67 & 12.36 \\
Rubricitos policromatófilos & 27.30 & 21.79 \\
Metarubricitos & 56.13 & 59.56 \\
Índice de maduración eritroide & & 3.28 \\
Mieloblastos & 1.93 & 2.18 \\
Promielocitos & 2.71 & 3.04 \\
Mielocitos neutrófilos & 6.80 & 4.32 \\
Metamielocitos neutrófilos & 13.27 & 5.76 \\
Abastonados neutrófilos & 4.60 & 29.47 \\
Segmentados neutrófilos & 36.60 & 33.33 \\
Mielocitos eosinófilos & 4.32 & 2.67 \\
Metamielocitos eosinófilos & 6.02 & 2.56 \\
Abastonados eosinófilos & 7.85 & 6.17 \\
Segmentados eosinófilos & 15.12 & 7.99 \\
Mielocito basófilo & 0.00 & 0.58 \\
Metamielocito basófilo & 0.78 & 0.44 \\
Abastonado basófilo & 0 & 0.57 \\
Segmentado basófilo & 0 & 0.91 \\
Índice de maduración mieloide & & \\
& & 6.40 \\
\hline
\end{tabular}

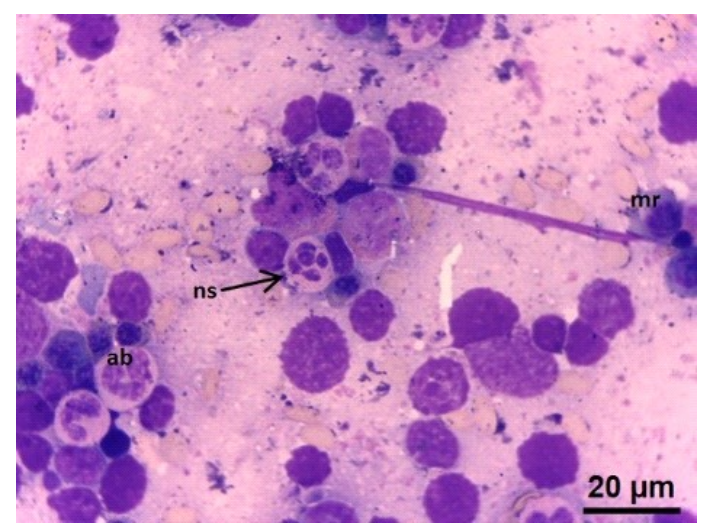

Figura 4. Médula ósea de feto de alpaca de 288.4 días. (ab) Abastonado neutrófilo. (ns) netrófilo segmentado. Tinción Wright. 100x

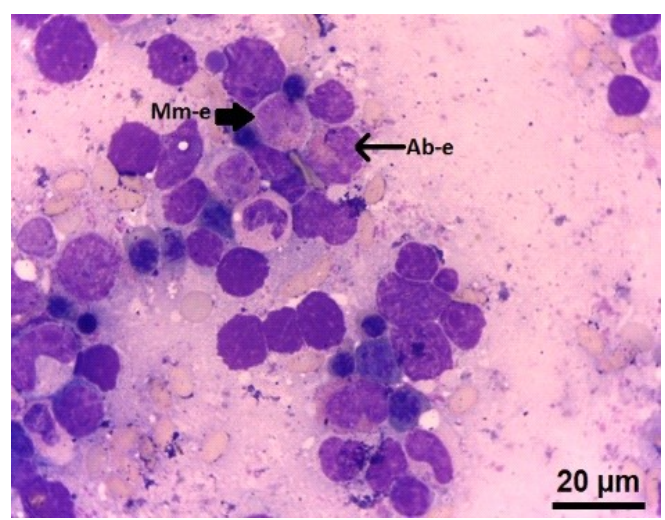

Figura 5. Médula ósea fetal de alpaca de 267.6 días. (Mm-e) Metamielocito eosinófilo. Nótese los gránulos eosinófilos en el citoplasma. (Ab-e) Abastonado eosinófilo. Tinción Wright. 100x 
Cuadro 7. Relación mieloide/eritroide $(\mathrm{M} / \mathrm{E})$ según el tercio de gestación en 18 fetos de alpaca (Vicugna pacos)

\begin{tabular}{|c|c|c|c|}
\hline $\begin{array}{l}\text { Tercio de } \\
\text { gestación }\end{array}$ & Feto & $\begin{array}{l}\text { Edad } \\
\text { (días) }\end{array}$ & $\begin{array}{l}\text { Relación } \\
\text { mieloide/ } \\
\text { eritroide } \\
(\mathrm{M} / \mathrm{E})^{1}\end{array}$ \\
\hline \multirow[t]{4}{*}{ Primer } & 1 & 75.2 & 0 \\
\hline & 2 & 86.7 & 0 \\
\hline & 3 & 96.2 & 0 \\
\hline & \multicolumn{2}{|c|}{ Promedio } & 0 \\
\hline \multirow[t]{6}{*}{ Segundo } & 4 & 121.4 & 0 \\
\hline & 5 & 138.7 & 0 \\
\hline & 6 & 141.0 & 0 \\
\hline & 7 & 201.5 & 0.20 \\
\hline & 8 & 219.2 & 0.73 \\
\hline & \multicolumn{2}{|r|}{ Promedio } & $0.47 \pm 0.27$ \\
\hline \multirow[t]{10}{*}{ Tercer } & 9 & 251.3 & 0.62 \\
\hline & 10 & 253.9 & 0.58 \\
\hline & 11 & 267.6 & 0.76 \\
\hline & 12 & 278.7 & 0.44 \\
\hline & 13 & 288.4 & 1.07 \\
\hline & 14 & 289.6 & 0.83 \\
\hline & 15 & 308.7 & 0.74 \\
\hline & 16 & 311.3 & 0.77 \\
\hline & 17 & 334.0 & 0.46 \\
\hline & 18 & 337.1 & 0.60 \\
\hline Promedio & \multicolumn{3}{|c|}{$0.69 \pm 0.19$} \\
\hline \multicolumn{4}{|c|}{$\begin{array}{l}1 \text { Dividiendo el porcentaje de células de } \\
\text { línea granulocítica entre las células } \\
\text { nucleadas de la línea eritroide, en un conteo } \\
\text { de } 500 \text { células }\end{array}$} \\
\hline
\end{tabular}

sen et al., 1994). De esta forma se puede sugerir que los cambios fisiológicos y anatómicos de adaptación a elevadas altitudes tienden influencia sobre los componentes celulares de la médula ósea en alpacas y, por consiguiente, durante su desarrollo fetal.
Cuadro 8. Estadísticos de la Prueba de Mann-Whitney aplicado a los valores de la relación mieloide/eritroide del segundo y tercer tercio de gestación en fetos de alpaca

\begin{tabular}{lc}
\hline U de mann-Whitney $^{1}$ & 5 \\
W de Wilcoxon & 20 \\
Z & -2.458 \\
Sig. Asintótica (bilateral) & 0.014
\end{tabular}

(p)

Sig. Exacta (unilateral) $\quad 0.013^{2}$

${ }^{1}$ Variable de agrupación: tercio de gestación

${ }^{2}$ No corregido para empates

La relación mieloide/eritroide difiere entre tercios de gestación

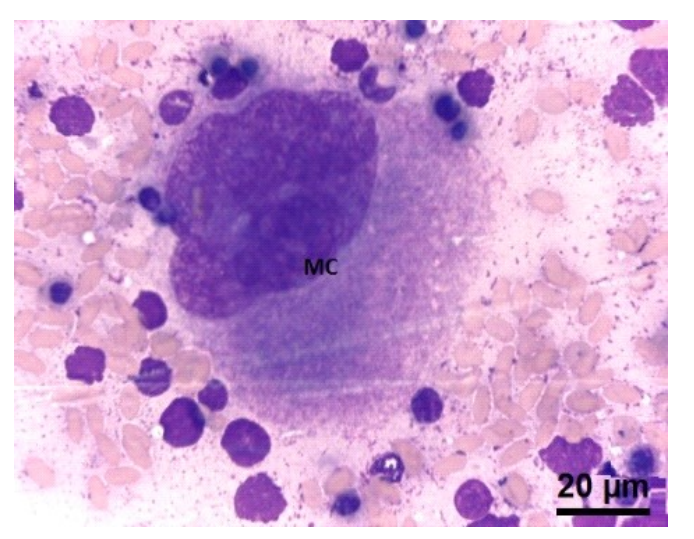

Figura 6. Médula ósea fetal de alpaca de 337.1 días. Célula precursora de serie trombocítica. (MC) Megacariocito. Nótese el núcleo lobulado y su gran tamaño. Tinción Wright. 100x

\section{Conclusiones}

- Los componentes celulares pertenecientes a las líneas hematopoyéticas en fetos de alpaca son morfológicamente y 


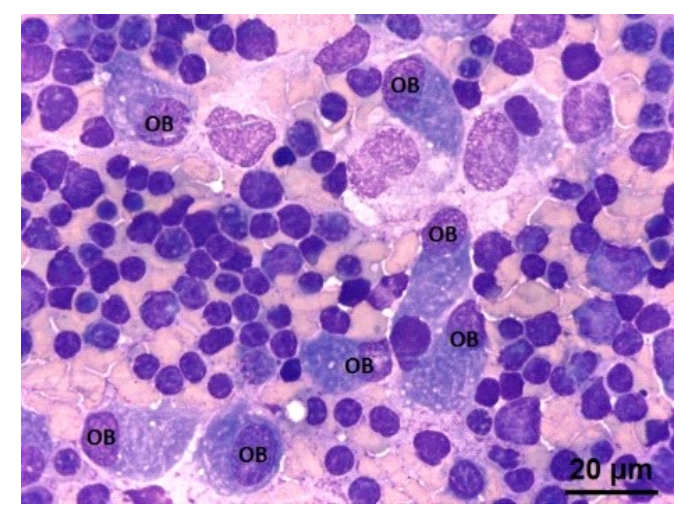

Figura 7. Médula ósea de un feto de alpaca de 334 días. (OB) Osteoblasto, célula con baja relación núcleo citoplasma. Evidentes nucléolos y citoplasma basófilo. Tinción Wright. 100x

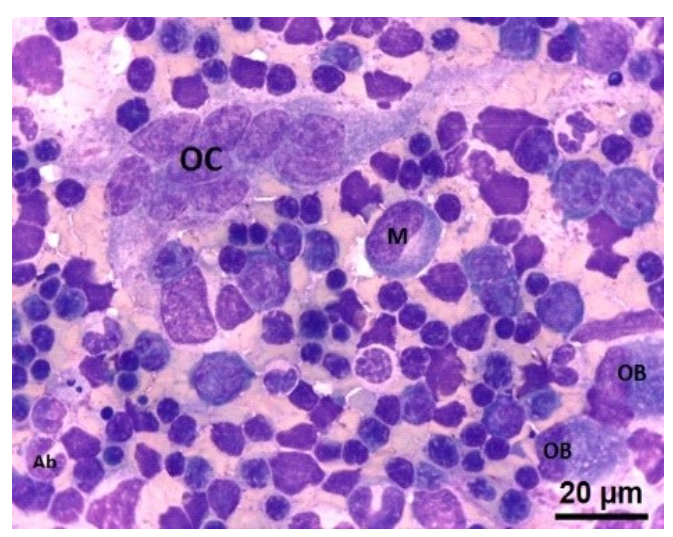

Figura 8. Médula ósea de un feto de alpaca de 334 días. (OC) Osteoclasto, célula muy grande multinucleada con citoplasma basófilo. (OB) Osteoblastos, (M) Mielocito neutrófilo, $(\mathrm{Ab})$, Abastonado neutrófilo. Tinción Wright. 100x

morfométricamente similares a otros mamíferos domésticos a partir de los 201.5 días de edad gestacional.

- Los componentes celulares eritroides nucleados en última fase de maduración en la médula ósea durante el último ter- cio gestacional de la alpaca son porcentualmente más elevados que en otros mamíferos domésticos.

- Los componentes celulares granulocíticos en la médula ósea de los fetos de alpaca son porcentualmente menores que en otros mamíferos domésticos.

- La relación mieloide/eritroide en la médula ósea de fetos de alpaca en el segundo y tercer tercio gestacional difiere estadísticamente.

- La médula ósea no tiene un rol primario como órgano linfoide durante el desarrollo fetal en la alpaca.

\section{Literatura Citada}

1. Andreasen CB, Gerros TC, Lassen ED. 1994. Evaluation of bone marrow cytology and stainable iron content in healthy adult llamas. Vet Clin Pathol 23: 38-42. doi: 10.1111/j.1939-165x.1994.tb00671.x

2. Arias W, Sandoval N, Chavera A, Manchego A. 2011. Caracterización de la citoarquitectura esplénica fetal de alpacas (Lama pacos). Rev Inv Vet Perú 22: 81-88. doi: 10.15381/rivep.v22i2.273

3. Battista JM, Tallmadge RL, Stokol T, Felippe MJB. 2014. Hematopoiesis in the equine fetal liver suggest inmune preparedness. Inmunogenetics 66: 635649. doi: 10.1007/s00251-014-0799-9

4. Coskun S, Chao H, Vasavada H, Heydari K, Gonzales N, Xin Zhou, Crombrugghe B, Hirschi K. 2014. Development of the fetal bone narrow niche and regulation of HSC quiescence and homing ability by emerging osteolineage cells. Cell Reports 9: 581590. doi: 10.1016/j.celrep.2014.09.013

5. Coskun S, Hirschi KK. 2010. Establishment and regulation of the HSC niche: Roles of osteoblastic and vascular compartments. Birth Defects Res C Embryo Today 90: 229-242. doi: 10.1002/ bdrc. 20194 
6. Fowler M. 2011. Medicine and surgery of camelids. $3^{\text {th }}$ ed. Iowa: Wiley-Blackwell. $630 \mathrm{p}$.

7. Gazitua FJ, Corradini P, Ferrando G, Raggi LA, Parraguez VH. 2001. Prediction of gestacional age by ultrasonic fetometry in llamas (Lama glama) and alpaca (Lama pacos). Anim Reprod Sci 66: 81-92. doi: 10.1016/S03784320(01)00083-5

8. Gekas C, Dieterlen-Levre F, Orkin SH, Mikkola HK. 2005. The placenta is a niche for hematopoietic stem cells. Dev. Cell 8: 365-375. doi: 10.1016/ j.devcel.2004.12.016

9. Grindem CB, Neel JA, Juopperi TA. 2002. Cytology of bone marrow. Vet Clin North Am Small Anim Pract 32: 13131374. doi: 10.1016/s0195-5616(02)00052-9

10. Harvey JW. 2010. Bone marrow examination. In: Harvey JW. Atlas of veterinary hematology: blood and bone marrow of domestic animals. Philadelphia, USA: Saunders. p 83-161.

11. Jain N. 1986. Veterinary hematology. Schalm's. $4^{\text {th }}$ ed. Philadelphia, USA: Lea \& Febiger. $1221 \mathrm{p}$.

12. Martínez de Merlo EM. 2008. Atlas de citología clínica del perro y del gato. Zaragoza: Servet. 408 p.

13. Mendoza G, Echevarría L, Llerena $C$, Castro A, Domínguez M, Gómez S, Ghezzi M, et al. 2013. Comparación morfológica entre el útero fetal y el útero adulto de la alpaca (Vicugna pacos) y la llama (Lama glama). Salud Tecnol Vet 1: 1-6. doi: 10.20453/stv.v1il.103

14. Montenegro JI. 2006. Caracterización histológica del timo en fetos de alpacas. Tesis de Médico Veterinario. Lima: Univ. Nacional Mayor de San Marcos. 65 p.

15. Morin DE, Garry FB, Weiser MG. 1993. Hematologic responses in llamas with experimentally-induced iron deficiency anemia. Vet Clin Palhol 22: 81-88. doi: 10.1111/j.1939-165X.1993.tb00657.x
16. Morrison SJ, Weissman IL. 1994. The long-term repopulating subset of hematopoietic stem cells is deterministic and isolatable by phenotype. Immunity 1: 661673. doi: 10.1016/1074-7613(94)-90037-x

17. Naziji S, Maleki K. 1998. Biochemical analysis of serum and cerebrospinal fluid in clinically normal adult camels (Camelus dromedarius). Res Vet Sci 65: 83-84. doi: 10.1016/S0034-5288(98)-90032-7

18. Palis J, Robertson S, Kennedy M, Wall C, Keller G. 1999. Development of erythroid and myeloid progenitors in the yolk sac and embryo proper of the mouse. Development 126: 5073-5084.

19. Pessa-Morikawa T, Niku M, Livanainen A. 2012. Fetal bovine bone marrow is a rich source of CD34+ hematopoietic progenitors with myelo-monocitic colony-forming activity. Dev Comp Inmunol 36: 572-577. doi: 10.1016/ j.dci.2011.09.014

20. Quispe E. 2011. Adaptaciones hematológicas de los camélidos sudamericanos que viven en zonas de elevadas altitudes. Rev Complutense Cienc Vet 5: 1-26.

21. Reynafarje HC, Faura J, Paredes A, Villavicencio D. 1968. Erythrokinetics in high-altitude-adapted animals (llama, alpaca, and vicuña). J Appl Physiol 24: 93-97. doi: 10.1152/jappl.1968.24.1.93

22. Smith BB, Reed PJ, Pearson EG, Long P, Lassen ED, Watrous WJ, Lovelady $S$, et al. 1991. Erythrocyte dyscrasia, anemia, and hypothyroidism in chronically underweight llamas. J Am Vet Med Assoc 198: 81-88.

23. Tiedemann K, van Ooyen B. 1978. Prenatal hematopoiesis and blood characteristics of the cat. Anat Embryol 153: 243-267.

24. Tornquist SJ. 2009. Clinical pathology of llamas and alpacas. Vet Clin North Am Food Anim Pract 25: 311-322. 10.1016/j.cvfa.2009.03.004

25. Weiss DJ, Wardrop KJ. 2011. Schalm's veterinary hematology. $6^{\text {th }} \mathrm{ed}$. Iowa: John Wiley. 1232 p. 